\title{
EDITORIAL
}

\section{Plan Nacional de Ciencia, Tecnología e Innovación}

El 2006 el Consejo Nacional de Ciencia, Tecnología e Innovación Tecnológica CONCYTEC desarrolló el Plan Nacional Estratégico de Ciencia, Tecnología e Innovación para la Competitividad y el Desarrollo Humano 2006-2021 PNCTI (1). En la formulación participaron los sectores estatal, académico y privado.

El PNCTI fue elaborado para encaminar al país hacia un desarrollo industrial, capaz de brindar productos con valor agregado que nos permita ser más competitivos a nivel internacional. Actualmente, los productos peruanos son en gran parte materias primas vendidas a precios muy bajos. Está claro que para ser más competitivos es necesario contar con tecnologías propias desarrolladas para nuestros productos o nuestra realidad, de tal manera de poder explotar nuestras ventajas competitivas. Es por ello que las prioridades del PNCTI se centran en los sectores:

1. Agropecuario y agroindustrial (por ejemplo, fibras naturales, nutracéuticos, mejoramiento genético, etc.).

2. Pesca y acuicultura marina y continental (por ejemplo, genética, nutrición y sanidad, etc.).

3. Minería y metalurgia (por ejemplo, minerales no metálicos, nano-materiales, etc.).

4. Forestal (por ejemplo, semillas de especies nativas, manejo de bosques, etc.).

5. Energía (por ejemplo, biodiesel, hidroenergía, eficiencia energética, etc.).

6. Telecomunicaciones (por ejemplo, telesalud, teleeducación, TIC para gestión productiva, etc.).

7. Turismo (por ejemplo, histórico-arqueológicas, turismo ecológico y cultural, etc.).

Las ingenierías son las principales disciplinas generadoras de tecnologías para obtener nuevos productos, que una vez aceptados en el mercado se convierten en innovaciones. Son precisamente las innovaciones las que nos permitirán alcanzar la competitividad deseada. Por lo tanto, las ingenierías juegan un papel importante en el PNCTI, pues desarrollan tecnologías a partir de conocimientos científicos para solucionar problemas que impiden que las industrias sean competitivas.

El PNCTI contempla la vinculación entre la empresa, la academia, el Estado y la sociedad civil como una de sus estrategias para alcanzar sus objetivos. Otras de las estrategias principales del PNCTI es incentivar y promover a investigadores, quienes son el eje principal para el avance en ciencia, tecnología e innovación. Contar con un reglamento de calificaciones de investigadores (2) es un aspecto importante para el cumplimiento de esta estrategia. Por todo ello, el PNCTI tiene la visión de llevar al Perú a una economía basada en el conocimiento.

\section{Referencias bibliográficas}

1. CONCYTEC. Plan nacional estratégico de ciencia, tecnología e innovación para la competitividad y el desarrollo humano, PNCTI 2006 - 2021. Lima: CONCYTEC, 2006.

2. Sistema Nacional de Ciencia, Tecnología e Innovación Tecnológica-SINACYT. Reglamento de calificaciones y registro de investigadores en ciencia y tecnología. El Peruano. 2015, p. 567978.

Celso De La Cruz Casaño Editor 